\title{
Heterologous mannitol-1-phosphate dehydrogenase gene over-expression in Parachlorella kessleri for enhanced microalgal biomass productivity
}

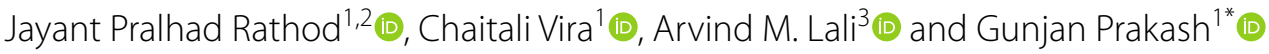

\begin{abstract}
Background: Microalgae have tremendous potential in $\mathrm{CO}_{2}$ sequestration, bioenergy, biofuels, wastewater treatment, and high-value metabolites production. However, large-scale production of microalgae is hampered due to photo-inhibition in outdoor cultivation. Mannitol, as an osmolyte, is known to relieve the stress produced under different abiotic stress conditions during the growth of a photosynthetic organism.

Results: In the present study, Mannitol-1-phosphate 5-dehydrogenase (Mt1D) was over-expressed to study the effect of mannitol over-production in Parachlorella kessleri under high-light induced stress. Over-expression of Mt1D led to $65 \%$ increased mannitol content in the transformed P. kessleri compared to that of wild type. Mannitol transformant demonstrated $>20$-fold reduction in reactive oxygen species generation and 15\% higher biomass productivity when grown in outdoor cultivation with high-light irradiance of $1200 \mu \mathrm{mol}$ photons $\mathrm{m}^{-2} \mathrm{~s}^{-1}$.

Conclusions: The current study establishes that a higher mannitol concentration provides stress shielding and leads to better acclimatization of transgenic microalgae against high-light generated stress. It also led to reduced ROS generation and improved growth of microalga under study. Thus, overexpression of the Mt1D gene in microalgae can be a suitable strategy to combat high-light stress.
\end{abstract}

Keywords: Microalgae, Mannitol, Abiotic stress, High-light, ROS

\section{Background}

Microalgae play an instrumental role in $\mathrm{CO}_{2}$ sequestration, thus helping mitigate greenhouse gases [1]. They are known to be the most promising organisms for "high volume-low cost" commodities like biofuel and "high cost-low volume" products like carotenoids, omega-3 fatty acids, vitamins [2,3]. Cultivating marine algae is less resource-intensive than that of freshwater one because it excludes the use of arable land and freshwater [4]. Outdoor cultivation in sunlight is the preferred method of

\footnotetext{
*Correspondence: g.prakash@ictmumbai.edu.in

${ }^{1}$ DBT-ICT Centre for Energy Biosciences, Institute of Chemical Technology, Mumbai, India

Full list of author information is available at the end of the article
}

cultivation due to the lower cost of cultivation at a large scale. However, high-light irradiance causes photo-inhibition due to the over-absorption of light energy beyond the microalgae capacity to use it for carbon fixation [5]. The excess light generates reactive oxygen species (ROS), which is detrimental for microalgal growth [5-7]. These cumulative factors hinder achieving economically feasible biomass productivity in outdoor cultivation. Closed cultivation of microalgae, using photobioreactor employing artificial light of low intensity has thus gained impetus in the last two decades. However, the technology has not yet matured to the level of commercial implementation [8]. Various engineering and biological solutions have thus been adopted to reduce the photo-inhibition 
in open cultivation. Scavenging ROS through compatible solutes or antioxidant enzymes is one of the primary mechanisms to mitigate abiotic stress resistance in microalgae $[9,10]$. Compatible solutes like trehalose, glyceinebetain, and mannitol also demonstrate ROS scavenging activity, provide osmoregulation, act as energy storage, and reduce power sink molecules. Mannitol, a sugar alcohol, is known to have all these properties and has been reported to be functional in plants against multiple abiotic stresses $[11,12]$ by over-expression of mannitol pathway genes.

Mannitol-1-phospahate converted from fructose6-phosphate to mannitol-1- phosphate using mannitol-1-phosphate dehydrogenase (Mt1D) enzyme and subsequently convert it to mannitol by mannitol1-phosphatase (M1pase) enzyme [13] by microorganisms. Overexpression of $M t 1 D$ gene in wheat, eggplant, sorghum, maize, and peanut has been shown to impart tolerance to salinity, drought stress and/or improved plant height/biomass [14]. The M1pase over-expression has also led to mannitol over-production in a cyanobacterium and Escherichia coli [11, 15]. The presence of mannitol synthesis genes has been reported in micro and macroalgae [16-18] like plants and other organisms. Therefore, enhancing mannitol content by overexpression of either one or both the genes might be helpful in the mitigation of light-induced stress in microalgae.

P. kessleri is a marine alga with high lipid content and thus is suitable for biodiesel (high volume-low cost) production at a large scale $[19,20]$. It is also being cultivated to synthesize lutein (low volume-high cost) [21]. Therefore, it is an ideal species to be used in an algal biorefinery for the overall sustainability of algal cultivation for biofuel. In outdoor cultivation, P. kessleri has been reported to undergo photo-inhibition due to high-light irradiance, resulting in retardation of cell growth [22] and lower biomass productivity in outdoor cultivation. In the present study, the first gene of the mannitol pathway $(M t 1 D)$ was overexpressed in P. kessleri to study its impact on the cell growth under high-light irradiance, i.e., photo inhibiting conditions.

\section{Methods}

\section{Culture, media, and growth conditions}

Walne's medium was used to grow and maintain wildtype (WT) P. kessleri. For transformation, P. kessleri was shifted to tris acetate phosphate (TAP) medium [22], and transformant was maintained on solid TAP agar containing $15 \mathrm{mg} \mathrm{l}^{-1}$ hygromycin (Hi-media, India). Both WT and transformant cultures were maintained on Walne's medium under a continuous light intensity of $75 \mu \mathrm{mol}$ photons $\mathrm{m}^{-2} \mathrm{~s}^{-1}$ on an incubator shaker (Eppendorf) at $25^{\circ} \mathrm{C}$ and $100 \mathrm{rpm}$.

\section{Plasmid construction and transformation}

$M t 1 D$ gene (GenBank DQ660889.10) isolated from the genomic DNA of E. coli was a generous gift [15]. The full-length cloned gene was amplified by polymerase chain reaction (PCR) using forward primer $5^{\prime}$-CAC CATGAAAGCATTACATTTTGG- $3^{\prime}$ and reverse primer 5'-TTATTGCATTGCTTTATAAGCG-3'. PCR was executed at initial denaturation of $94{ }^{\circ} \mathrm{C}$ for $5 \mathrm{~min}$ followed by 34 cycles of denaturation at $94{ }^{\circ} \mathrm{C}$ for 1 min, annealing at $52{ }^{\circ} \mathrm{C}$ for $1 \mathrm{~min}$ and extension at 72 ${ }^{\circ} \mathrm{C}$ for 2 min with a final extension of 5 min at $72{ }^{\circ} \mathrm{C}$. The PCR products were analyzed on $1 \%$ agarose gel.

The extracted PCR product from the above reaction containing $\mathrm{CACC}$ at $5^{\prime}$ forward side was cloned into pENTR vector (Invitrogen) using the manufacturer's protocol. Gateway ${ }^{\circledR}$ technology was used to clone $M t 1 D$ gene in pH7RWG2.0 vector with the help of Gateway ${ }^{\circledR}$ LR Clonase ${ }^{\circledR}$ II kit using manufacturer's protocol (Invitrogen). pH7RWG2.0 vector harbouring $M t 1 D$ gene was transformed in P. kessleri using particle bombardment (Bio-Rad) protocol as described earlier [22]. In short, $1 \mathrm{mg}$ gold carrier particle (Seashell Technology, USA) of approximately $550 \mathrm{~nm}$ were coated with $2 \mu \mathrm{g}$ of plasmid and bombarded at a pressure of $900 \mathrm{psi}$ and a distance of $6 \mathrm{~cm}$. Post bombardment, the plates were kept in the dark for overnight incubation followed by scraping of cells and plating the cells onto selective TAP agar medium containing $15 \mathrm{mg}^{-1}$ hygromycin for 3-4 weeks.

\section{Molecular analysis}

USING TAKARA KIT, genomic DNA was isolated from $1 \times 10^{7}$ cells of transformed and wild-type $P$. kessleri culture [22]. The presence of $M t 1 D$ gene in the genomic DNA of transformant P. kessleri was confirmed by PCR. The plasmid harbouring the $M t 1 D$ gene was used as a positive control and the PCR products were analyzed on $1 \%$ agarose gel. SDS PAGE was performed by extracting total soluble protein from WT and transformed P. kessleri cells. Total soluble protein extracts were prepared using $10 \mathrm{ml}$ of WT and transformed $P$. kessleri cells. The cells were harvested by centrifugation at 10,000 $\mathrm{rpm}$ for $5 \mathrm{~min}$ and resuspended in $200 \mu \mathrm{l}$ extraction buffer ( $50 \mathrm{mM}$ HEPES, $5 \mathrm{mM} \mathrm{MgCl}$, $1 \mathrm{mM}$ EDTA, $1 \mathrm{mM}$ EGTA, $10 \%$ glycerol, $1 \%$ Triton-X 100, $2 \mathrm{mM}$ benzamidine hydrochloride, $2 \mathrm{mM} \mathrm{6-ami-}$ nocaproic acid, $0.5 \mathrm{mM}$ PMSF, $10 \mathrm{mM}$ DTT). The samples were denatured at $95^{\circ} \mathrm{C}$ for $5 \mathrm{~min}$. The extracted proteins were separated on $12 \%$ acrylamide gel by 
SDS-PAGE and the proteins were stained by standard silver staining protocol [23].

\section{High-light stress experiment}

As mentioned earlier, P. kessleri WT and transformant were grown in a specially designed environmental chamber (EC) [7]. EC is made up of glass, and the temperature was maintained at $25{ }^{\circ} \mathrm{C}$ using the air conditioner. The cultures were exposed to diurnal variations of sunlight as the sole source of light, with natural light intensity reaching up to $1200 \mu \mathrm{mol}$ photons $\mathrm{m}^{-2} \mathrm{~s}^{1}$ during the period of experimentation. All the experiments were done in triplicates.

\section{Growth, nitrate, and pigment analysis}

Growth of the algal cultures was monitored by measuring their optical density at $750 \mathrm{~nm}$ using a UV-Visible spectrophotometer (UV 2550, Shimadzu) at a regular interval of $24 \mathrm{~h}$. At the end of the experiment, dry cell weight of the culture was determined by centrifuging the culture broth and washing the cell pellet thrice with distilled water to remove any traces of medium salts. The washed pellet was dried at $70{ }^{\circ} \mathrm{C}$ until a constant weight was obtained. For nitrate consumption analysis, cells were centrifuged at $8000 \mathrm{rpm}$ and supernatant was analyzed by spectrophotometric method at $220 \mathrm{~nm}$ [24]. The standard graph was prepared using sodium nitrate $\left(2-20 \mathrm{mg} \mathrm{l}^{-1}\right)$ solution. Chlorophyll a, chlorophyll b, and total carotenoids were determined as described by Kumari et al. 2020 and Rathod et al. 2020 at stationary phase $[25,26]$. In short, the algal cultures were centrifuged at $5000 \mathrm{rpm}$ to get the pellet. The supernatant was removed, and $99.9 \%$ methanol was added to the pellet for pigments extraction. The samples were kept in dark for $30 \mathrm{~min}$. The samples were centrifuged, and supernatant was taken to measure the absorbance at 665,652 , and $480 \mathrm{~nm}$. Standard equations were used to calculate the chlorophyll a, chlorophyll $b$, and total carotenoids $[25,26]$.

\section{Quantification of mannitol production}

Mannitol was extracted from dried biomass of $P$. kessleri cultures (both WT and transformant) at stationary phase using the method described by Jang et al. 2003 [27]. Briefly, dried biomass was crushed in liquid nitrogen and resuspended in $1 \mathrm{ml}$ of distilled water. This sample was kept in boiling water bath for 15 min which was then cooled and filtered through $0.2 \mu \mathrm{m}$ filter.

Mannitol content was determined by HPLC on Agilent 1200 series (Agilent Technologies, USA) using Bio-Rad
Aminex HPX-87H Column $(250 \times 4.6 \mathrm{~mm})$ with $5 \mathrm{mM}$ sulphuric acid in the mobile phase at a flow rate of 0.6 $\mathrm{mL} / \mathrm{min}$. Column temperature was maintained at $45^{\circ} \mathrm{C}$. The eluted samples were detected by RI detector [15]. Commercially available mannitol (Sigma) was used as the standard.

\section{Estimation of reactive oxygen species and membrane damage}

The extent of high-light stress in P. kessleri was determined towards the end of the growth phase. ROS presence was determined by colorimetric estimation of extracellular hydrogen peroxide $\left(\mathrm{H}_{2} \mathrm{O}_{2}\right)$ production according to the method detailed by Rathod et al., 2016 [22]. The extent of membrane damage due to generation of the ROS was assessed by estimating the intracellular malondialdehyde (MDA) content. Thiobarbituric acid (TBA) assay was employed for MDA content determination as per the protocol described by Rathod et al. 2016 [22].

\section{Statistical analysis}

Transformants and WT analysis were performed in triplicates. Collected data were compared using Student's $t$ test. Statistical analysis were performed using Microsoft excel.

\section{Results \\ Overexpression of Mt1D}

The $M t 1 D$ gene (1149 bp) was cloned downstream of the cauliflower mosaic virus (CaMV) $35 \mathrm{~S}$ promoter. Transformation of $M t 1 D$ gene was carried out in P. kessleri by particle bombardment method. In this case, only one transformant (M1) for P. kessleri was observed. The single $P$. kessleri mannitol expressing transformant (M1) was confirmed by PCR using Mt1D gene-specific primers as depicted in Fig. 1.

M1 was sub-cultured under selection pressure till 20th generation to make sure its stability by PCR confirmation for $M t 1 D$ presence. The $M t 1 D$ gene codes for 382 amino acids, translating to $41.15 \mathrm{kDa}$ of protein (GenBank: ABG54389.1). The presence of $\sim 41 \mathrm{kDa}$ band in transformed P. kessleri and its corresponding absence in wildtype culture (Fig. 2) indicated the successful integration of heterologous $M t 1 D$ gene and its successful translation to the corresponding protein in $P$. kessleri.

\section{Comparative study of wild-type and transformant under natural high light}

WT and M1 were subjected to light stress by cultivating them under natural light irradiance of $1200 \mu \mathrm{mol}$ photons $\mathrm{m}^{-2} \mathrm{~s}^{-1}$ in EC. Under high-light irradiance, the optical density of wild type and M1 was similar until log phase (144 h) as depicted in Fig. 3. However, WT growth 


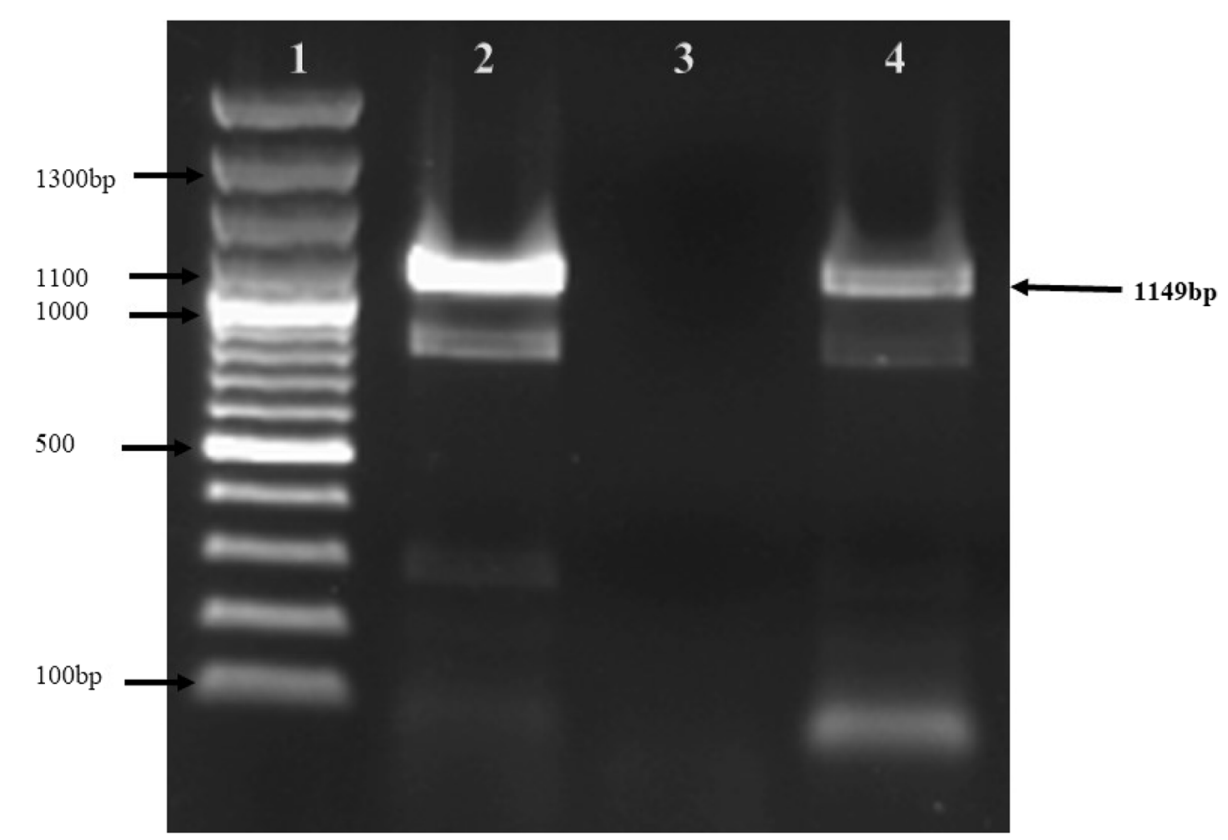

Fig. 1 PCR analysis for Mt1D gene with gene-specific primers in wild-type and transformed P. kessleri. Lane 1: 100 bp ladder (from bottom to top $1000 \mathrm{bp}, 1100 \mathrm{bp}, 1200 \mathrm{bp}$, and $1300 \mathrm{bp}$ ), lane 2: PCR amplicon in positive control, lane 3: amplicon of wild-type P. kessleri, and lane 4: PCR amplicon of Mt1D transformant

was super succeeded by M1 when the cultures started entering in the stationary phase. $M t 1 D$-expressing $P$. kessleri culture displayed a $65 \%$ increase in mannitol content (Fig. 4) compared to that of WT. Concurrently, M1 exhibited $13 \%$ increased nitrate consumption which also correspondent to the similar percentage increase in biomass productivity (Fig. 3). The absolute amount of mannitol formed in P. kessleri WT, as well as the transformant (Fig. 4), was found to be higher. A drastic reduction $(\sim 20$ fold) in $\mathrm{H}_{2} \mathrm{O}_{2}$ content release was obtained in $\mathrm{M} 1$ compared to WT when both were grown at $1200 \mu \mathrm{E}$ (Table 1). A > 1.5-fold decrease in the internal concentration of MDA was obtained for M1 as compared to that of WT cells (Table 1).

An overall increase in pigment content was also observed for M1 compared to that of WT P. kessleri for both chlorophyll a (31\%) and b (16\%) as well as for the total carotenoids $(8 \%)$ concentration as depicted in Table 2. The reduced chlorophyll antenna size of M1 compared to that of WT (indicated by higher chlorophyll $\mathrm{a} / \mathrm{b}$ ratio) was observed.

\section{Discussion}

\section{Overexpression of Mt1D}

CaMV 35S promoter is a commonly used promoter and has been used to express varied genes in different microalgae like Dunaliella bardawil, D salina, Chlorella ellipsoidea, C. vulgaris, and Haematococcus pluvialis [28-30]. CaMV 35S promoter has also been found to be functional in P. kessleri [31].

Only one transformant was observed in Mt1D transformation. This contrasted with the earlier report where higher transformation efficiency was reported for Trehalose phosphate phosphatase gene expression in P. kessleri using the same methodology [31]. In the present case, the low transformation efficiency of $M t 1 D$ could be attributed to the source of the gene (E. coli) which was prokaryotic in origin. The eukaryotic origin genes have led to more transformants in microalgae, including $P$. kessleri [22, 32, 33]. The codon optimization of Mt1D would have helped increase the transformation efficiency however could not be attempted because of the absence of codon optimization table for $P$. kessleri.

The $M t 1 D$ was successfully transformed into $P$. kessleri and was confirmed by PCR using $M t 1 D$ gene-specific primers and was found to be stable until the 20th generation. Transformation was further confirmed at protein expression level by SDS PAGE analysis.

\section{Comparative study of WT and transformant under natural high light}

Mannitol is a well-known osmolyte that protects the cell against salt, drought, and chilling stress in different organisms [14, 18, 34, 35]. Over-expression of $M t 1 D$ in the Solanum tuberosum resulted in fresh weight and 

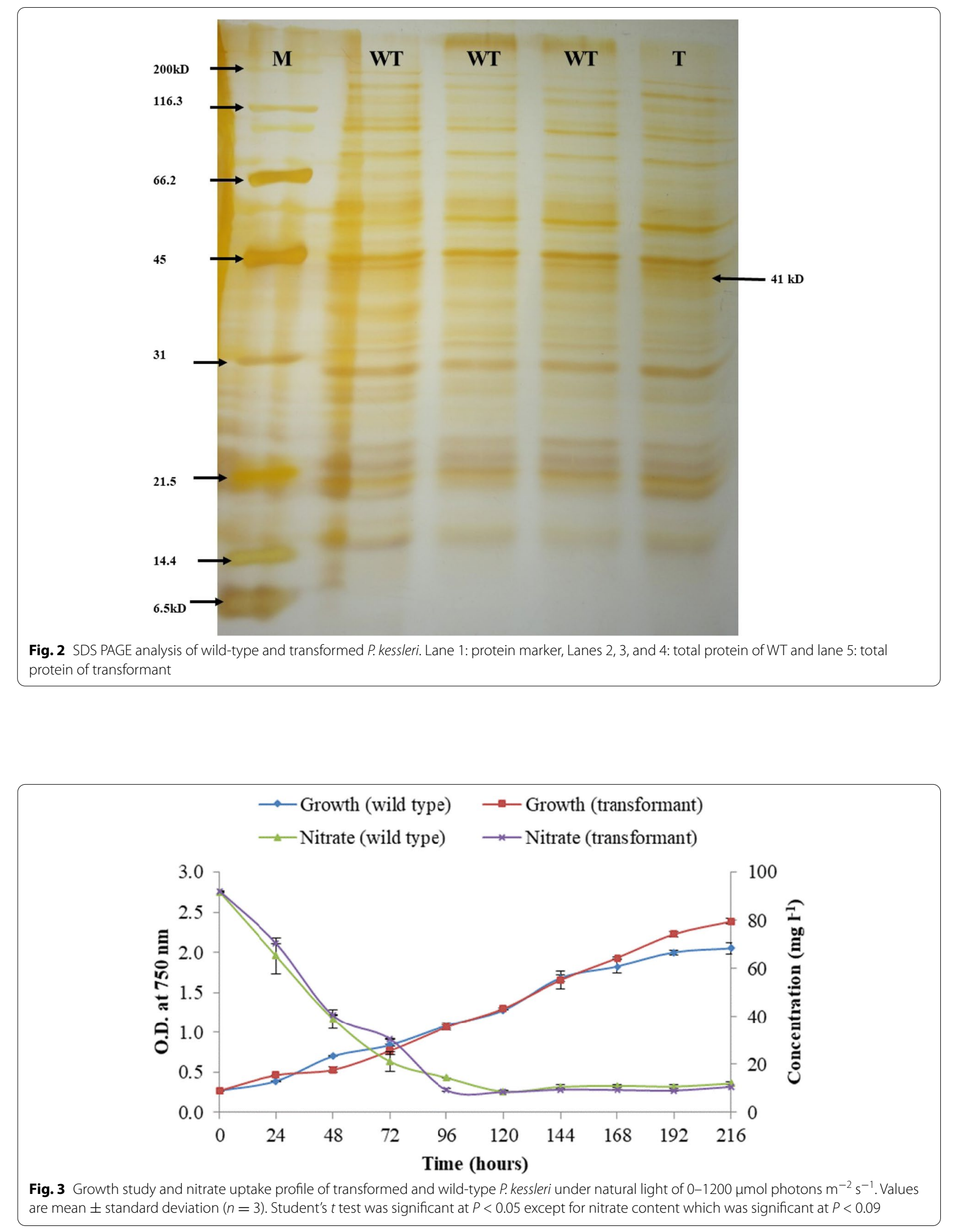


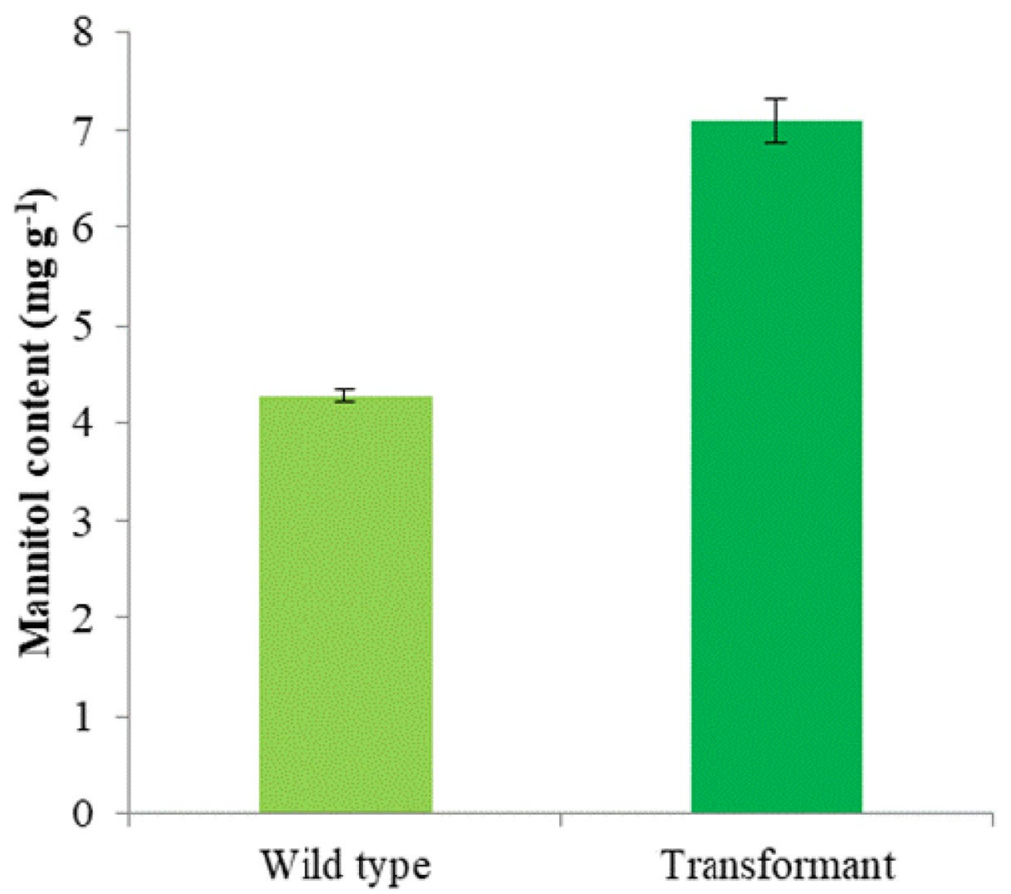

Fig. 4 Mannitol content of wild-type and transformed $P$. kessleri in the light regime up to $1200 \mu \mathrm{mol}$ photons $\mathrm{m}^{-2} \mathrm{~s}^{-1}$. Values are mean \pm standard deviation $(n=3)$. Student's $t$ test was significant at $P<0.05$

Table 1 Comparison of stress parameters for wild-type and transformed P. kessleri in the light regime of 0-1200 $\mu \mathrm{mol}$ photons $\mathrm{m}^{-2} \mathrm{~s}^{-1}$

\begin{tabular}{lll}
\hline Stress parameters & Wild type & Transformant \\
\hline ROS (nM/10^4 cells) & $6.77 \pm 0.22$ & $0.33 \pm 0.07$ \\
MDA $\left(\boldsymbol{\mu} \mathbf{M ~ g}^{-1}\right)$ & $278.18 \pm 27.6$ & $163.82 \pm 3.99$ \\
\hline
\end{tabular}

Values are mean \pm standard deviation $(n=3)$

Student's $t$ test was significant at $P<0.05$

Table 2 Pigments studies of wild-type and transformed P. kessleri in the light regime up to $1200 \mu \mathrm{mol}$ photons $\mathrm{m}^{-2} \mathrm{~s}^{-1}$

\begin{tabular}{lll}
\hline Pigments & Wild type & Transformant \\
\hline Carotenoids $\left(\mathbf{m g ~ g}^{-1}\right)$ & $2.51 \pm 0.27$ & $2.71 \pm 0.07$ \\
Chlorophyll a $\left(\mathbf{m g ~ g}^{-1}\right)$ & $4.62 \pm 0.43$ & $6.04 \pm 0.30$ \\
Chlorophyll b $\left(\mathbf{m g ~ g}^{-1}\right)$ & $1.57 \pm 0.32$ & $1.82 \pm 0.15$ \\
Chlorophyll a/b & $2.97 \pm 0.33$ & $3.32 \pm 0.12$ \\
\hline
\end{tabular}

Values are mean \pm standard deviation $(n=3)$

height enhancement [36]. The amount of mannitol formed in P. kessleri WT and transformant was much higher than that of transgenic petunia, tomato, and wheat plants over-expressing $M t 1 D$ gene $[28,37,38]$. This higher amount could be due to the marine origin of $P$. kessleri.
ROS generation and cellular lipid membrane damage were measured to investigate oxidative stress management by over-expression of mannitol in transformed $P$. kessleri cultures under high light stress conditions. Environmental stresses such as drought, salinity, and low temperature create ROS, which is mitigated by activating various oxidases and peroxidases in microalgae [39]. In marine microalgae, $\mathrm{H}_{2} \mathrm{O}_{2}$ has been reported to cause inhibition of photosynthesis enzymes [40]. The protective role of mannitol in dealing with hydroxyl radicals has also been reported in Petunia. Mannitol was found to react with hydroxyl radicals to form a mannitol radical which was then converted to mannose in the presence of oxygen, thus protecting the cell from oxidative damage [37].

The excessive generation of intracellular ROS due to oxidative stress also causes lipid peroxidation of cell membrane resulting in MDA synthesis [41]. Reduction in both $\mathrm{H}_{2} \mathrm{O}_{2}$ and MDA content indicated that over-expression of $M t 1 D$ gene which resulted in increased mannitol production facilitated stress relief in transformed $P$. kessleri cells. A higher reduction in $\mathrm{H}_{2} \mathrm{O}_{2}$ compared to that of MDA was significant because its half-life is more than other ROS molecules, and it diffuses faster through the membranes, causing severe damage leading to inhibition of multiple photosynthesis enzymes in marine microalgae [40]. Hema et al. 2014 have also observed increased 
resistance to oxidative stress linked to a reduction in superoxide radical production in transgenic plants by over-expression of $M t 1 D$ gene [12].

In transgenic tomato, over-expression of bacterial $M t 1 D$ gene increased total chlorophyll content against multiple abiotic stresses [28]. One of the possible reasons for the increase in chlorophyll content in M1 could be the requirement of NADH, the reducing power for mannitol-1-phosphate dehydrogenase enzyme to synthesize mannitol-1-phosphate from fructose-6-phosphate [11]. The requirement of NADH might have been fulfilled by increasing the overall pigment composition to enhance photosynthesis by chlorophyll pigments in case of $P$. kessleri and transgenic tomato [28].

The reduced chlorophyll antenna size of M1 was observed, suggested it to be a better performer under high-light intensities due to decreased absorption of incident light. Reduced chlorophyll antenna size phenomenon was also obtained in P. kessleri when Trehalose Phosphate Synthase was over-expressed [22]. Reduced chlorophyll antenna size is preferred under high-light growth conditions and is helpful to achieve higher growth densities in microalgae $[7,42]$.

In summary, mannitol over-production by over-expression of the first gene of mannitol pathway led to increasing mannitol production and pigments which could combat high-light irradiance generated stress. The cumulative effects of all the effects resulted in increased biomass productivity of $P$. kessleri by $15 \%$ under high-light stress conditions in $M t 1 D$ transformant.

The mechanism of mannitol action against stress release is not fully understood. However, few hypotheses relating to membrane lipid and protein stabilization, scavenging of free oxygen molecules, and maintaining the turgor of cells at low water activity have been proposed in plants [43]. There are very few reports of osmolytes overexpression in microalgae and cyanobacteria. Choline oxidase, glycinebetaine, and trehalose have been reported to enhance growth under different abiotic stress conditions in the microalgae $[31,44,45]$. To the best of our knowledge, before the present work, the effect of over-production of mannitol against light induced abiotic stress has not reported in microalgae.

\section{Conclusion}

Over-expression of $M t l D$ gene in marine and oleaginous P. kessleri resulted in higher levels of mannitol accumulation and protection under high-light induced stressed growth conditions. Thus, mannitol over-expression can be an efficient way to mitigate light-mediated abiotic stress in microalgae.

\section{Abbreviations}

CaMV: Cauliflower mosaic virus; Mt1D: Mannitol-1-phosphate dehydrogenase; M1 pase: Mannitol-1-phosphatase; ROS: Reactive oxygen species; MDA: Malondialdehyde; TBA: Thiobarbituric acid.

\section{Acknowledgements}

JPR and CV are thankful to the Council of Scientific and Industrial Research (CSIR), Government of India, New Delhi, for providing the fellowship during the above research work.

\section{Authors' contributions}

Conception and design of experiment: GP and AML. Experimentation and analysis: JPR, CV, and GP. Drafting and critical revision of the manuscript: GP and JPR. Funding: AML. All authors read and approved the final manuscript.

Funding

This work was supported by Department of Biotechnology, Ministry of Science \& Technology, Government of India, (No. BT/EB/ICT-Extension/2012/).

Availability of data and materials

Not applicable

\section{Declarations}

Ethics approval and consent to participate

Not applicable

\section{Consent for publication}

All authors have the consent for the publication.

\section{Competing interests}

The authors declare that they have no competing interests.

\section{Author details}

${ }^{1}$ DBT-ICT Centre for Energy Biosciences, Institute of Chemical Technology, Mumbai, India. ${ }^{2}$ ADT's Shardabai Pawar Mahila Arts, Commerce \& Science College, Baramati, Maharashtra, India. ${ }^{3}$ Department of Chemical Engineering, Institute of Chemical Technology, Mumbai, India.

Received: 13 September 2021 Accepted: 18 February 2022 Published online: 28 February 2022

References

1. Lee JS, Lee JP (2003) Review of advances in biological $\mathrm{CO}_{2}$ mitigation technology. Biotechnol Bioprocess Eng 8:354

2. Behera S, Singh R, Arora R, Sharma NK, Shukla M, Kumar S (2015) Scope of algae as third generation biofuels. Front Bioengineer Biotechnol 2:90

3. Abdullah MA, Ahmad A, Shah SMU, Shanab SMM, Ali HEA, Othman MF (2016) Integrated algal engineering for bioenergy generation, effluent remediation, and production of high-value bioactive compounds. Biotechnol Bioprocess Engineer 21:236-249

4. Amin S (2009) Review on biofuel oil and gas production processes from microalgae. Energy Conversion Manage 50:1834-1840

5. Torzillo G, Pushparaj B, Masojidek J, Vonshak A (2003) Biological constraints in algal biotechnology. Biotechnol Bioprocess Engineer 8:338-348

6. Melis A (2009) Solar energy conversion efficiencies in photosynthesis: minimising the chlorophyll antennae to maximise efficiency. Plant Sci J. 177:272-280

7. Patil S, Prakash G, Lali AM (2020) Reduced chlorophyll antenna mutants of Chlorella saccharophila for higher photosynthetic efficiency and biomass productivity under high light intensities. J Appl Phycol 16:1-9

8. Kumar BR, Mathimani T, Sudhakar MP, Rajendran K, Nizami AS, Brindhadevi K, Pugazhendhi A (2021) A state of the art review on the cultivation of algae for energy and other valuable products: application, challenges, and opportunities. Renew Sustain Energy Rev 138:110649

9. Leong YK, Chang JS (2020) Bioremediation of heavy metals using microalgae: Recent advances and mechanisms. Bioresource Technol 303:122886 
10. Gauthier MR, Senhorinho GNA, Scott JA (2020) Microalgae under environmental stress as a source of antioxidants. Algal Res 52:102104

11. Jacobsen JH, Frigaard NU (2014) Engineering of photosynthetic mannitol biosynthesis from $\mathrm{CO}_{2}$ in a cyanobacterium. Metab Engineer 21:60-70

12. Hema R, Vemanna RS, Sreeramulu S, Reddy CP, Senthil-Kumar M, Udayakumar M (2014) Stable expression of $m t / D$ gene imparts multiple stress tolerance in finger millet. PloS One. 9:e99110

13. Yu C, Cao Y, Zou H, Xian M (2011) Metabolic engineering of Escherichia coli for biotechnological production of high-value organic acids and alcohols. Appl Microbiol Biotechnol 89:573-583

14. Bhauso TD, Thankappan R, Kumar A, Mishra GP, Dobaria JR, Rajam MV (2014) Over-expression of bacterial mtID gene confers enhanced tolerance to salt-stress and water-deficit stress in transgenic peanut (Arachis hypogaea) through accumulation of mannitol. Austral J Crop Sci 8:413

15. Reshamwala SM, Pagar SK, Velhal VS, Maranholakar VM, Talangkar VG, Lali AM (2014) Construction of an efficient Escherichia coli whole-cell biocatalyst for D-mannitol production. J Biosci Bioengineer 118:628-631

16. Bonin P, Groisillier A, Raimbault A, Guibert A, Boyen C, Tonon T (2015) Molecular and biochemical characterization of mannitol-1-phosphate dehydrogenase from the model brown alga Ectocarpus sp. Phytochemistry. 117:509-520

17. Tonon T, Li Y (2017) Mason SM (2017) Mannitol biosynthesis in algae: more widespread and diverse than previously thought. New Phytologist 213:1573-1579

18. Chi S, Liu T, Liu C, Jin Y, Yin H, Xu X, Li Y (2018) Characterization of mannitol metabolism genes in Saccharina explains its key role in mannitol biosynthesis and evolutionary significance in Laminariales. bioRxiv 243402

19. Ahmad I, Fatma SZ, Yazdani S, Kumar S (2013) DNA barcode and lipid analysis of new marine algae potential for biofuel. Algal Res 2:10-15

20. Li X, Pribyl P, Bisova K, Kawano S, Cepak V, Zachleder V, Cizkova M, Branyikova I, Vitova M (2013) The microalga Parachlorella kessleri--A novel highly efficient lipid producer. Biotechnol Bioengineer 110:97-107

21. Heo J, Shin DS, Cho K, Cho DH, Lee YJ, Kim HS (2018) Indigenous microalga Parachlorella sp. JD-076 as a potential source for lutein production: Optimization of lutein productivity via regulation of light intensity and carbon source. Algal Res 33:1-7

22. Rathod JP, Prakash G, Vira C, Lali AM (2016) Trehalose phosphate synthase overexpression in Parachlorella kessleri improves growth and photosynthetic performance under high light conditions. Prep Biochem Biotechnol. 46:803-809

23. Vira C, Prakash G, Rathod JP, Lali AM (2016) Cloning, expression, and purification of Chlamydomonas reinhardtii CC-503 sedoheptulose 1, 7-bisphosphatase in Escherichia coli. Preparative Biochem Biotechnol 46:810-814

24. Carvalho AP, Meireles LA, Malcata FX (1998) Rapid spectrophotometric determination of nitrates and nitrites in marine aqueous culture media. Analusis 26:347-351

25. Kumari S, Vira C, Lali AM, Prakash G (2020) Heterologous expression of a mutant Orange gene from Brassica oleracea increases carotenoids and induces phenotypic changes in the microalga Chlamydomonas reinhardtii. Algal Res 47:101871

26. Rathod JP, Vira C, Lali AM, Prakash G (2020) Metabolic Engineering of Chlamydomonas reinhardtii for Enhanced $\beta$-Carotene and Lutein Production. Appl Biochem Biotechnol 190:1457-1469

27. Jang IC, Oh SJ, Seo JS, Choi WB, Song SI, Kim CH, Kim JK (2003) Expression of a bifunctional fusion of the Escherichia coli genes for trehalose-6-phosphate synthase and trehalose-6-phosphate phosphatase in transgenic rice plants increases trehalose accumulation and abiotic stress tolerance without stunting growth. Plant Physiol 131:516-524

28. Gupta B, Rajam MV (2013) Marker-free transgenic tomato with engineered mannitol accumulation confers tolerance to multiple abiotic stresses. Cell Dev Biol. 2:2

29. Schurr R, Kuehnle A (2014) Microalgae crop improvement: tools for quality control and molecular breeding. Industrial Biotechnol 10:237-243

30. Mathieu-Rivet E, Kiefer-Meyer MC, Vanier G, Ovide C, Burel C, Lerouge $P$, Bardor M (2014) Protein N-glycosylation in eukaryotic microalgae and its impact on the production of nuclear expressed biopharmaceuticals. Front Plant Sci 5:359
31. Rathod JP, Prakash G, Pandit R, Lali AM (2013) Agrobacterium-mediated transformation of promising oil-bearing marine algae Parachlorella kessleri. Photosynth Res 118:141-146

32. Cerutti H, Johnson AM, Gillham NW, Boynton JE (1997) A eubacterial gene conferring spectinomycin resistance on Chlamydomonas reinhardtii: integration into the nuclear genome and gene expression. Genetics. 145:97-110

33. Wu-Scharf D, Jeong BR, Zhang C, Cerutti H (2000) Transgene and transposon silencing in Chlamydomonas reinhardtii by a DEAH-box RNA helicase. Science. 290:1159-1162

34. Prabhavathi V, Yadav JS, Kumar PA, Rajam MV (2002) Abiotic stress tolerance in transgenic eggplant (Solanum melongena $\mathrm{L}$.) by introduction of bacterial mannitol phosphodehydrogenase gene. Mole Breed 9:137-147

35. Madsen MA, Semerdzhiev S, Amtmann A, Tonon T (2018) Engineering mannitol biosynthesis in Escherichia coli and Synechococcus sp. PCC 7002 using a green algal fusion protein. ACS Synth Biol. 7:2833-2840

36. Askari A, Pepoyan A (2012) Overexpression of $m t / D$ gene in potato (solanum tuberosum L.), cv. Arinda improves salt tolerance. Adv Environ Biol:2646-2654

37. Chiang YJ, Stushnoff C, MCSay AE, Jones ML, Bohnert HJ (2005) Overexpression of mannitol-1-phosphate dehydrogenase increases mannitol accumulation and adds protection against chilling injury in petunia. J Am Soc Horticultural Sci 130:605-610

38. Ramadan AM, Eissa HF, Hassanein SE, Azeiz AA, Saleh OM, Mahfouz HT, El-Domyati FM (2013) Increased salt stress tolerance and modified sugar content of bread wheat stably expressing the $m t / D$ gene. Life Sci J 10:2348-2362

39. Liu W, Au DW, Anderson DM, Lam PK, Wu RS (2007) Effects of nutrients, salinity, pH and light: dark cycle on the production of reactive oxygen species in the alga Chattonella marina. J Experiment Marine Biol Ecol 346:76-86

40. Dummermuth AL, Karsten U, Fisch KM, Konig GM, Wiencke C, Gauthier MR, Senhorinho GNA, Scott JA (2020) Microalgae under environmental stress as a source of antioxidants. Algal Res 52:102104

41. Choudhary M, Jetley UK, Khan MA, Zutshi S, Fatma T (2007) Effect of heavy metal stress on proline, malondialdehyde, and superoxide dismutase activity in the cyanobacterium Spirulina platensis-S5. Ecotoxicol Environ Safety 66:204-209

42. Patil S, Lali AM, Prakash G (2020) Reduced chlorophyll antenna mutants of Chlorella saccharophila for higher photosynthetic efficiency and biomass productivity under high light intensities. J Appl Phycol 32:1559-1567

43. Wisselink HW, Weusthuis RA, Eggink G, Hugenholtz J, Grobben GJ (2002) Mannitol production by lactic acid bacteria: a review. Int Dairy J 12:151-161

44. Deshnium P, Los DA, Hayashi H, Mustardy L, Murata N (1995) Transformation of Synechococcus with a gene for choline oxidase enhances tolerance to salt stress. Plant Mole Biol 29:897-907

45. Hema R, Senthil-Kumar M, Shivakumar S, Reddy PC, Udayakumar M (2007) Chlamydomonas reinhardtii, a model system for functional validation of abiotic stress responsive genes. Planta. 226:655-670

\section{Publisher's Note}

Springer Nature remains neutral with regard to jurisdictional claims in published maps and institutional affiliations. 